\title{
LA LITERATURA LATINA COMO TRADUCCIÓN E IMITACION
}

\author{
Bartolome Segura Ramos
}

Universidad de Sevilla

\section{RESUMEN}

Este trabajo aspira a plantearse con cierta profundidad la interesante cuestión de la imitatio antigua, como origen esencial de toda literatura, por cuanto el primer modelo literario, si bien nacido de la poesía oral, la Ilíada, no fue de otra manera como se hizo. El término imitatio, por otra parte, puede corresponder en buena medida a lo que modernamente se conoce como «intertextualidad». El trabajo debe servir para comprender mejor el proceso literario, su origen y alcance, la naturaleza, en último término, del arte de escribir, que algunos consideran, erróneamente, una especie de creación ex nihilo carente de toda base real.

¿Habrá comenzado toda literatura por no ser sino mera traducción de otra, supuestamente más desarrollada? ¿Cómo nació la griega, por ejemplo? Desde luego, si la llíada es el primer espécimen de la literatura griega, debemos decir en primer lugar que cuando fue fijada por escrito, ese poema llevaba «rodando» de boca en boca varias centurias, y por tanto sólo necesitaba para ser puesto por escrito que se inventase la escritura. Por tanto, si entendemos por literatura los monumentos escritos únicamente, la Ilíada será el origen de la literatura griega (y de la Occidental, si así queremos verlo), pero aún queda por dilucidar si ese tipo de poema y su historia son un producto estrictamente original de la antigua Hélade, o si no es éste el caso.

Si tenemos presente que la epopeya homérica forma parte de un universo épicoreligioso (pues el elemento religioso es más que probable que haya sido parte importante en el nacimiento de toda literatura, al menos, como impulso inicial y en las formas 
más elementales de la misma) que no sólo se extiende fuera del mundo helénico, sino que realmente precede a éste en bastante tiempo, es decir, que la epopeya que cuaja en el poema que conocemos como Ilíada existía con anterioridad en otras civilizaciones y pueblos (sumerios, acadios, hetitas, urritas), en los cuales se había plasmado de una u otra forma, de tal manera que cabe comparar el poema griego de que disponemos con aquellos representantes previos, o con los magros restos que nos han llegado, entonces habremos de reconocer que si bien la Ilíada constituye el comienzo de la literatura griega, este poema no es, ni por la forma ni por el contenido, original del mundo helénico.

Así que habremos de convenir en que tampoco la literatura griega fue un producto autóctono, ni por la forma ni por el fondo. Otra cuestión es (y por cierto nada baladí) que desde sus mismos inicios así como por el desarrollo ulterior esta literatura alcanzase un nivel de enorme calidad. Ahora bien, ¿se puede hablar en este caso propiamente de traducción? No parece que estemos en condiciones de afirmar o negar nada al respecto; tampoco se puede excluir tajantemente. Pero, ¿cómo puede haber traducción si no hay escritura? ¿Y en el plano meramente oral? ¿No cabe que leyendas orientales penetrasen en territorio griego por esa vía?

Porque este de la oralidad es un mundo al que estamos menos acostumbrados, para el que, por así decirlo, tenemos menos respuestas, en el que estamos menos capacitados para hacernos una idea, para imaginar cómo pueden suceder las cosas. Pero sí están claros, por el contrario, determinados «universales» que tienen que ver con el comportamiento de la lengua en general. Por ejemplo, cómo se aprende el lenguaje, cómo se produce la mímesis de acento, tono, giros linguíísticos; cómo se transmiten todos estos aspectos de una lengua, cómo, precisamente por medio del recitado y del canto, es todavía más fácil la expansión de las creaciones orales (letanías, carmina, poemas, cuentos), cómo el teatro en su forma más simple y elemental, las ceremonias religiosas, los ritos de primavera, la danza, las fiestas populares, contribuye de forma decisiva al aprendizaje, transmisión y perpetuación de creaciones de ese carácter. Por tanto, de esa forma las expresiones poéticas, las primeras epopeyas acadias, pongamos por caso, o urritas, han podido pasar al mundo griego, tomar en él carta de naturaleza y encontrar el modo de tarsvasarse a la nueva lengua. ¿No cabe entonces la posibilidad de «traducir» un viejo poema sumerio oral a la vieja lengua griega, del mismo modo como se traduce una canción en inglés a nuestra lengua?

De modo que no parece disparatado afirmar que, de la misma manera como podemos decir que no existe una sola raza pura, sino que todas son fruto del cruce y del mestizaje, así también podríamos aseverar que no hay una sola literatura que haya nacido de forma autóctona, sin mezcla ni influencia de otras literaturas, como también que no existe una lengua impermeable al influjo de las demás, sea en el plano léxico, o el sintáctico, e incluso en el fonético-morfológico.

Pero así como es muy probable que la literatura griega, oral, pudo haberse ido formando en tiempos muy remotos respecto a la aparición de la llíada, e incluso haber coexistido con aquellas manifestaciones orientales en las que, como hemos dicho, debió originarse, también resulta poco creíble que la literatura latina fuese algo más que simples balbuceos con anterioridad a la influencia arrolladora de la literatura griega, influencia que, de hecho, cuando viene a operarse, es cuando habían transcurrido cinco siglos casi de los comienzos de la misma. 
Pues, ¿con qué contamos de literatura latina antes de que la griega se dejara sentir en ella? Es cierto que cabe pensar en manifestaciones rústicas (aquellos carmina escritos en el horridus ille/ numerus Saturnius de que hablaba Horacio en su Epíst. II 1, $157-8$ ), tanto las que eran así por cuanto versaban sobre ceremonias para propiciar las siembras y las cosechas, como posiblemente también los llamados carmina conuiualia, o canciones para amenizar los banquetes, que es probable que al igual que los kléua andrón o «hazañas de los héroes» que gustaban de escuchar los reyes y príncipes de la época micénica, tratasen también de enaltecer los hechos, de armas, especialmente, de los señores de la guerra en el festín presentes. Pero además, por otro lado, sabemos por Tito Livio (VII 2, 3-7: cum uis morbi...ludi quoque scaenici...instituti dicuntur, del año 364 a.C.) que, por influencia justamente de los etruscos, hubo en suelo itálico, con independencia de los griegos de la Magna Grecia, manifestaciones teatrales que, aunque su alcance y contenido son discutidos, bastan no obstante para probar que antes de los griegos los romanos conocieron el teatro y establecieron los fundamentos de esta clase de representaciones, en las que el elemento humano principal, el actor, recibía, como es bien sabido, el nombre etrusco de histrio. Así que entre unas cosas y otras, bien que de forma elemental y poco perfeccionada, manifestaciones poéticas y teatrales debieron tener lugar en la península itálica con anterioridad a la influencia griega.

Pero si consideramos, por un lado, que los griegos llevaban en el Sur de Italia desde poco después de comenzar el primer milenio antes de Cristo, y tenemos presente, por otro, que los primeros atisbos propiamente literarios en latín no tienen lugar hasta bien entrado el siglo tercero del mismo milenio, no deja de sorprendernos (si no olvidamos al mismo tiempo que la Ilíada llevaba puesta por escrito alrededor de quinientos años antes de la ocasión a que nos venimos refiriendo) el hecho de que los cercanos griegos no hubiesen influido en este aspecto que aquí nos ocupa con anterioridad a cuando lo hicieron. ¿Dónde estaban los latinos a lo largo de esos cuatrocientos o quinientos años, que no se enteraron de que un poco más al Sur había un pueblo culto y sabio que sabía ya casi todo sobre cualquier aspecto de la vida?

Suponer, por otro lado, que los latinos se hallaban mental y espiritualmente en la misma situación en la que se encontraban los griegos del segundo milenio, digamos, cuando presumiblemente recibieron el impulso decisivo de la civilización oriental que les llevó a cantar «los hechos de los héroes» de boca en boca, sería desconocer la índole y circunstancias históricas de uno y otro pueblo hasta grados insostenibles. Pues, para ceñirnos a los latinos, el pueblo que ahora nos compete primordialmente, ¿no es verdad que en los albores de la Historia no pasaba de ser un grupúsculo inculto e ignorante, rodeado de otros pueblos agresivos, tan pobres y miserables como él, con los que hubo de batirse a la desesperada para sobrevivir? ¿Y no es cierto que, habituado ya a la guerra y a la conquista, a luchar con la tierra y luego con el mar, no paro de rodar por esa áspera pendiente, arrastrando cuanto encontraba a su paso? ¿Acaso tenía tiempo o ganas de cantar y crear con las palabras, como no fueran ensalmos para obtener buenas cosechas y auspicios para ganar las batallas? ¿Y qué? ¿Hasta dónde podía llegar un pueblo así, entre el cultivo de la tierra y la gloria bélica, sino a tropezar con los mismísimos griegos del Sur itálico, a los que por fin conoció, a la hora justamente de someterlos, para tal vez entonces hallar que aquellos advenedizos, aunque inferiores a ellos por la fuerza de las armas, los superaban holgadamente en el dominio del espíritu, algo que quizá ellos, los latinos, habían descuidado más de la cuenta? 
La llamada literatura latina arcaica, la que viene representada por Livio Andronico, Nevio y Ennio, parece surgir de repente, de la nada, en virtud de un sencillo «hágase la luz». Pero, ¿es esto posible? ¿Cómo debemos imaginarnos el salto de la nada literaria a los primeros especímenes de la literatura latina, los cuales, por cierto, ofrecen un alto nivel poético tanto por la forma como por el contenido? ¿No hemos quedado en que hasta que la literatura griega no entró en contacto con los romanos y les insufló su arte los latinos no habían pasado de toscos, cuando no torpes, pasos, que difícilmente habrían alcanzado altas metas literarias ni siquiera en el transcurso de los siglos e incluso de los milenios?

Creo que antes que nada conviene asentar el principio de que todo oficio se aprende y se transmite, partiendo de la base, claro está, de que exista semejante oficio. Así, de generación en generación, se transmiten el conocimiento y las diferentes «téchnai», tanto en el arte, como en la guerra, en la arquitectura o el juego. Pues bien, en esta línea de pensamiento no cabe duda de que los romanos pronto desarrollaron, con la constante práctica, el arte de la guerra, el mando y la política. Les faltaba la literatura. ¿Puede transmitirse también un «oficio» de un pueblo o sociedad a otro pueblo o sociedad diferente, igual que en el interior de una misma sociedad? ¿Qué clase de contacto se requiere para que tal cosa tenga lugar? ¿Pacífico? ¿De dominio y sumisión? ¿Cultural? Y, ¿cuánto tiempo se necesitaría para que tal contacto diera sus frutos?

Porque, en efecto, insistimos otra vez, la literatura latina no pudo surgir de la noche a la mañana. Menos mal, por tanto, que la historia parece que tuvo lugar de una forma comprensible: en su imparable proceso de conquista, Roma topó con los griegos del Sur de Italia , y, sistemáticamente, según su propio estilo, procedió a someter pueblos y ciudades (cf. la conocida inscripción del año 298 a. C.:Taurasia, Cisauna, Samnio cepit/subigit omne Loucanam). Hay que imaginar al mismo tiempo que no fue este el primer contacto con los griegos y su cultura, aunque sí el instante «esperado» para que por fin el choque entre ambas «culturas» produjera la chispa necesaria. Por ello, para justificar todos nuestros recelos y reticencias respecto a la forma como se originó la literatura del Lacio, hubo de ser un esclavo griego (de Tarento), Livio Andronico, quien, enrolado en la comitiva «cultural» del general victorioso, hiciese de nexo de unión entre una literatura, la griega, ya superdesarrollada, y otra, la latina, tan incipiente y pobre que, para hablar con propiedad, no existía. He aquí, pues, la forma, quizá la única pensable, en que se desarrollaron los acontecimientos: Roma conquista a los griegos de la Magna Grecia, con los que sin duda mantenía relaciones desde tiempos atrás y de los que había oído que poseían un arte literaria que a ellos faltaba casi por entero; los generales romanos, que, a diferencia de las tropas, de la plebe y de los esclavos, sí sabían leer y escribir, y que, estimulados por lo que habían visto a los griegos, sentían también deseos de conocer las mieles de las obras del espíritu, van a hallar ahora la ocasión de conseguir lo que anhelaban desde hacía tanto tiempo, a saber, probar en lengua latina lo visto y admirado en lengua griega. Un esclavo, culto y dotado, Andronico va a servir a este propósito: él introducirá en Roma el arte de la escritura artística a la mayor gloria de los señores de la guerra, semicultos y ambiciosos. Y, en efecto, Livio Andronico, respondiendo a los deseos de su amo, llevará a cabo una tarea original y excepcional: expresar en lengua latina lo que originariamente había sido en lengua griega, traduciendo la Odisea de Homero al latín (así es como en su Odussia traducirá Andronico el primer verso (I 1), que rezaba «Dime, Musa, del hombre superhábil», como uirum mihi, Camena, insece uersu- 
tum; y el verso I 45 «Oh padre nuestro, Crónida», como pater nostre, Saturni filie; así como el conocido y repetido verso (I 64) «Hijo mío, ¿qué palabras se han escapado del cerco de tus dientes", como mea puer, quid uerbi ex tuo ore supra/fugit?). El primer paso ya había sido dado, sólo quedaba proseguir la tarea hasta el infinito (no cabe duda de que cuando se da este paso y fructifica y quedan rastros de él. el mismo había sido precedido por múltiples intentos y por un caldo de cultivo que propiciaron la aparición y éxito de Andronico).

Por tanto, en cierto modo, la Odussia de Andronico no deja de ser, como primer atisbo de literatura latina que es, una creación ex nihilo, pero sólo por la inexistencia de otros monumentos literarios anteriores a esta obra, los cuales hemos de presuponer. Y justamente, detrás de este primer logro (al que es un griego el que llega, no lo olvidemos), vendrán otros, en hilera interminable ya, aunque al principio, todavía, de las manos de no romanos: pues Nevio (campaniense) y Ennio (de Rudias en Mesapia) no han nacido en Roma, sino que son personajes de la periferia, empapados, indudablemente, de la civilización griega.

De modo que ya hemos dado, aparentemente, el salto: de la oscura nada de la literatura latina, por un curioso juego de manos, presentamos a la consideración de la Historia los primeros especímenes de esta nueva literatura. Pero, ¿por dónde hemos empezado? Precisamente, por donde empezó la literatura griega. a saber, por la poesía épica. Porque, en efecto, este género se verá privilegiado desde el principio, siendo así que los más grandes éxitos de la nueva literatura corresponderán a él: Nevio con su Bellum Punicum, y Ennio con sus Annales remacharán la primacía del género.

Claro que estos dos últimos autores, si no romanos, como hemos señalado, pero tampoco griegos, no van a ejercer solamente este género: la épica será para ellos un género más entre sus otras preocupaciones literarias, que les llevarán a ser pioneros en diferentes géneros, sentando, de este modo. las bases de lo que será fundamentalmente la literatura latina en el futuro. Comenzaron por la épica, pero hay que reseñar que las epopeyas que osan escribir no lo serán de tema legendario, sino de asunto típicamente romano, lo que implica un atrevimiento y casi temeridad de su parte, y ello mismo a la vez nos habla de la capacidad creativa de estos pioneros de la literatura latina, cualidad que, dicho sea de paso, significa también que detrás de sus esfuerzos ha debido haber muchas probaturas, tanto de su parte como de la parte de otros que el tiempo ha olvidado.

Así que, amén de la épica, estos escritores han tanteado la sátira, una sátira que no será todavía el género, típicamente romano (fuesen ellos los inventores o no), tal como quedará definida por Lucilio en el siglo siguiente (s.II), pero que ya constituirá un barrunto de ella, y que en cualquier caso supone un intento arduo, especialmente por lo que hace a Ennio. Éste no se halla solo junto a Nevio (dejando de lado. por más antiguo, a Andronico), sino que más o menos por el mismo tiempo, además de ellos dos, surgirá otro escritor, igualmente no romano, sino de la periferia, Plauto (de Sársina, en Umbría), que dirigirá todos sus esfuerzos a otro género: la comedia.

Nevio y Ennio se dedicaron también al teatro. De su obra sólo nos quedan magros restos, pero por los títulos podemos apreciar el camino que siguieron. Estos títulos revelan que su labor consistió fundamentalmente en hacer versiones al latín de las obras que los dramaturgos griegos habían llevado a la escena (Nevio: Dánae, El caballo de Troya, Ifigenia; Ennio: Aquiles, Áyax, Alcmeón. Alejandro, Andrómaca prisionera, Erecteo, 
Hécuba, Medea, Telamón); los escasos fragmentos que han quedado no hacen sino confirmar esta suposición: estos escritores latinos habían entrado a saco en el rico repertorio poético de los autores griegos de los siglos V, IV y III, procurando extraer de semejante ubérrimo filón adaptaciones para el público romano que, en plena guerra contra Aníbal, presagiaba ya el inminente poderío de Roma y su imperio.

Sin embargo, es de Plauto de quien por primera vez en la historia de la literatura latina contamos con obras que han llegado completas hasta nosotros (veinte comedias y una parte de la Vidularia), y un material de tal extensión sí nos permite ya comparar copia y original, al menos parcialmente, con el fin de valorar hasta qué punto se ha llevado a cabo la traducción de las obras griegas y en qué otra medida comienzan a extenderse la costumbre y norma de la imitación. Pues todo el mundo sabe cuánto se ha hablado de contaminatio en Plauto, un término que, como casi siempre, significa cosas distintas para cada cual, pero que en realidad lo que quiere decir es simplemente que nuestro autor, al adaptar una obra griega al latín, entre los cambios que introducía no faltaba en ocasiones el recurso a escenas o pasajes provenientes de otras comedias, en principio, del mismo autor de origen. Los efectos de este procedimiento se manifiestan especialmente en comedias como el Miles o el Pseudolus. Pero no sólo Plauto, sino también posteriormente Terencio pondrá en práctica idéntico proceder, el cual, por cierto acabaría causando problemas a este último, quien en los prólogos de algunas de sus comedias se queja del «viejo poeta malévolo» que le echaba en cara, precisamente, contaminare algunas de sus obras (Cf. La andriana: versos 6-7 qui maleuoli/ueteris poetae maledictis respondeat. Verso 9: Menander fecit Andriam et Perinthiam; versos 13-14: "Los detalles que encajaban (entre una y otra obra), el autor confiesa haberlos trasladado de la Perintia a la Andriana y haberse servido de ellos como propios»; versos 15-16: "Eso es lo que esos censuran que haya hecho y en ello insisten, que no procede andar «contaminando» - contaminari - las comedias»; versos 18-19: «al acusarme a mí, acusan a Nevio, Plauto y Ennio, a los que este amiguito considera sus modelos»). Lo cual choca por más de una razón, puesto que, en realidad, como venimos afirmando, la literatura latina (y no sólo en sus orígenes) es fruto de la traducción e imitación de la griega, y ello fue práctica habitual de todo escritor: pero es que también el concepto que nosotros tenemos de plagio no se corresponde en absoluto (así como tampoco el de originalidad) con el que los antiguos pudiesen tener al respecto: los temas poéticos eran absolutamente libres y la originalidad consistía en el tratamiento más o menos novedoso del mismo tema. Así es como entre los dramaturgos griegos, los tres grandes tragediógrafos, Esquilo, Sófocles y Eurípides, llevaron a las tablas (y entre sí competían durante los días de las representaciones teatrales) asuntos tomados de las leyendas cíclicas, de las obras de Homero, de la mitología tradicional, y en ocasiones presentaban obras con el mismo o similar título, e idéntico contenido, sin que ello fuera óbice para que el jurado y el público apreciasen dichas obras por la forma en que había sido tratado un mismo tema, sin que en ningún caso viniese a cuento arremeter contra el colega que había prersentado una obra con el mismo argumento. Así que tanto más sorprendente se ofrece esta crítica del poeta al que alude Terencio, pues bien debía saber el supuesto poeta que esta era la situación real y que a nadie tenía por qué sorprender.

De modo que se puede afirmar sin temor a equivocarse que las comedias de Plauto y Terencio son al mismo tiempo traducciones, imitaciones y adaptaciones de originales 
griegos, sin que ello suponga irremediablemente menoscabo alguno del producto final y de la calidad del mismo. Ya hemos afirmado más arriba que los griegos actuaban de la misma manera entre sí (a nosotros se nos ocurre que sería vergonzoso un hecho de esta naturaleza, pero olvidamos que en realidad hacemos lo mismo, incluso de forma más descarada. Tomemos, por ejemplo, un género como el de la novela policíaca. ¿Por qué el lector avezado a este tipo de novelas sabe a las primeras de cambio quién es el asesino? Porque todas las novelas del género siguen una misma pauta; porque de hecho cualquier novela de la especie vale como representante del género; porque todas estas novelas son en realidad una y la misma novela. ¿Qué ocurre en el cinematógrafo con el llamado western? ¿No se reproducen hasta la saciedad las mismas situaciones, los mismos tópicos, los mismos gestos, los mismos argumentos, las mismas actitudes? ¿Consideramos por ello que tal director de cine ha plagiado a tal otro?). Con todo, al igual que, pese a lo dicho para los géneros y autores actuales, no deja de ser verdad que el plagio es algo que en ocasiones se practica y se reconoce fácilmente, de la misma manera es posible que la situación tuviese algún parecido en la Antigüedad: si un autor copiaba una obra a otro, ello era fácilmente detectable y sobre el autor en cuestión recaía un anatema. ¿Era esto lo que insinuaba el «viejo poeta malévolo» de Terencio? Éste, desde luego, no lo aceptaba en absoluto, y su defensa parece convincente (vide supra).

Hasta este momento hemos tenido en cuenta aquellos géneros por los que comenzo la literatura latina: en primer lugar, la épica: luego, la comedia y la tragedia; después la sátira en la primera versión más o menos titubeante de Ennio. Ahora compete proseguir el análisis al albur del surgimiento de los restantes géneros en la literatura, y veremos que lo importante en esta pesquisa no es tanto, lógicamente, desvelar la secuencia de los géneros literarios en Roma como la confirmación de que el procedimiento de aclimatación de los mismos a la lengua latina es siempre el mismo: traduciendo e imitando, adaptando, a los autores originales griegos y sus obras.

¿De dónde salió la sátira de Lucilio? Porque ese quintilianesco dicho (I.O. X 1, 93) de que satira quidem tota nostra est no parece claro que signifique inequívocamente que el género es totalmente romano (puede significar, por ejemplo, también que en ese género los romanos superaron a los griegos). Por tanto, cuando en manos de Lucilio la sátira adquirió su forma y contenido prácticamente definitivo, habría que preguntarse si el rico y osado escritor se sacó de la manga el género. Pero ya hemos dicho que Ennio había escrito una especie de sátira, que más que por la forma y el fondo, era sátira por el nombre y origen del mismo: algo así como mezcla de cosas diferentes. De dónde provenga a su vez semejante miscelánea, si hemos de ser coherentes, sólo podemos suponer que será de la literatura griega, como es natural. Así que si Lucilio fue el primus inuentor (prótos heuretés) del género, habrá que entender que lo fue en cuanto que, como afirmamos arriba, dio al mismo la forma y contenido por los que generalmente se lo reconoce.

Mas todavía quedaban algunos géneros bien cultivados y representados entre los griegos y que, sin embargo, entraron y se desarrollaron entre los romanos en último lugar: lírica, elegía y poesía bucólica o pastoral. ¿A qué se debió su tardía incorporación? Posiblemente, a una razón bien patente: los géneros que penetraron antes fueron aquellos que podíamos denominar géneros literarios «sociales» (épica, teatro, incluso sátira), en tanto que estos otros eran géneros que se adecuaban más bien a los individuos, aunque la lírica originaria fuese de hecho coral, pública y participativa. 
Mas para lo que a nosotros ahora nos compete lo importante es que estos géneros, cuando por fin fueron adaptados en Roma, tuvieron el mismo tratamiento que los precedentes: traducción e imitación. Así, por ejemplo, Catulo, aparte de imitar a destajo a los poetas alejandrinos, ofreció traducciones casi literales de algunos de aquellos poemas (cf., verbigracia, el poema 51, que traduce a Safó, y el 66, conocido como el rizo de Berenice, que traduce a Calímaco); los elegíacos por su parte imitaron precisamente a éste; Horacio, a Alceo, Safó, Píndaro (el venusino se vanagloriaba de ser el primero que había transportado la lírica griega a lengua latina: cf. $O$. XXX 13-14 princeps Aeolium carmen ad Italos/ deduxisse modos).

De hecho, los escritores latinos se esforzaron a lo largo del tiempo, sencillamente, por reproducir los logros de la literatura griega en lengua latina (pues, ¿qué otra cosa podían hacer?). Así es como, por ejemplo, Virgilio sigue para sus tres obras otros tantos modelos y originales griegos (en forma no demasiado alejada a como lo habían hecho los pioneros, Plauto, verbigracia), de tal manera que para la primera (las Bucólicas) tradujo e imitó muy de cerca a Teócrito. Véase, a manera de ilustración, cómo se reproducen los primeros compases de un Idilio de éste, Los Pastores (Noméis), también conocido como Para Coridón, donde leemos: Bato: ¿Dime, Coridón, de quién son estas vacas? ¿De Filondas?/ Coridón: No, de Egón. Me las ha entregado para que las apaciente. Bato: ¿No es cierto que se las ordeñaste todas anoche a escondidas?" Compárese a su vez con los primeros versos de la égloga III de nuestro poeta: Menalcas: «Dime, Dametas, ¿de quién es el ganado? ¿De Melibeo, tal vez.?» Dametas: «No, de Egón. Hace poco que me lo entregó Egón». Menalcas: "Ay, desgraciado ganado siempre las ovejas. Mientras él requiebral a Neera y teme que me prefiera a él,/ este guardián ajeno las ordeña dos veces a la hora./ y le sustrae el jugo al ganado y a los corderos la leche.s Igualmente, sabemos que lo mismo hizo con las Geórgicas, en las que siguió el ejemplo de Hesíodo («el viejo de Ascra»), para no hablar de la Eneida, en cuya primera parte imita la Odisea y en la segunda la llíada, llevando a cabo un experimento, en cierto sentido condenado al fracaso, puesto que pretendió crear ex nihilo, artificialmente, lo que en su origen había sido pura poesía oral y por tanto el resultado de cientos de años y, lo que es más significativo, de cientos de «poetas» que durante esos siglos ensayaron en vivo ante auditorios reales e interesados (festiva, política y económicamente) en el recitado que se les estaba ofreciendo. Pero, en fin, desde el mismo Homero comenzó ese aire artificial inherente a toda literatura, que sin embargo cabe subsanar de alguna manera, enfrentando los textos, y su elaboración, al público (por eso, el teatro, - bien entendido: pantomima, vodevil, musichall, y otras formas semejantes - es la única parte de la literatura que goza todavía -o podría gozar - de cierto carácter vivo en su creación (naturalmente, la mayor parte del teatro actual es literario en el mal sentido de la palabra).

Ahora bien, no cabe duda de que también la literatura latina pudo alcanzar su madurez, pues como hemos señalado más arriba la imitatio no es el plagio ni la parodia (cf. Franco Bellandi, Persio, Bolonia, 1996, pág. 65: (la poesía no es) pura tecnica imitati$v a$, ni tampoco sacheggio del lavoro altrui), sino la capacidad de crear siguiendo y aprovechando los logros que otros han alcanzado ya. De esta manera es como entendemos, dentro ya de la propia literatura latina, la imitatio de un poeta como Persio, que, como todo el mundo sabe, entró a saco en la obra de Horacio, las sátiras, especialmente, pero dándole un matiz distinto: al sacar de contexto las frases y combinarlas con otras de di- 
ferente origen el resultado alcanzado puede ser diametralmente opuesto. Véase, si no, a guisa de ilustración, una vez más. la comparación entre Horacio. Sát. II 3. 1 ss. y Persio 111 l ss. Primero. Horacio, quien dice entre otras cosas: Sic raro scribis, ut toto non quater anno/ membranam poscas (...)/iratus tibi quod uini somnique henignus/nil dignum sermone canas. Quid fiet? At ipsis/Saturnalibus huc fugisti sobrius./ Culpantur frustra calami imperitusque laborat,/ iratis natus paries dis atque poetis.. /Contemnere miser (...) Ahora, Persio: "Nempe haec assidue?" (...)/ stertimus, indomitum quod despumare Falernum/ Sufficiat... siccas insana canicula messes/iam dudum coquit et patula pecus omne sub ulmo est./Tum querimur crassus calamo quod pendeat umor/ (...) O miser inque dies ultra miser, hucine rerum/ uenimus/ (...) Effluis amens/ contemnere... Lo que ya está creado, ¿para qué volverlo a inventar otra vez? ¿No escribe todo el mundo con las mismas palabras y casi idénticas frases? ¿No existen los tópicos literarios, las situaciones mil veces repetidas? ¿Quién prohíbe reutilizar metáforas que alguien descubrió un día, pero de las que, como del lenguaje en general, nadie es dueño? La sabia imitatio, pues, se halla en la base de toda buena literatura: que nadie crea que es original porque genera extrañas frases o pensamientos absurdos o ininteligibles; se puede hablar con la lengua de todo el mundo (de la gente que habla desprevenidamente), se puede seguir el ejemplo acertado de otros, y sin embargo lograr una obra que siendo en cierto sentido lo mismo no se parece en nada. Como por ejemplo, Virgilio. O incluso Persio tal vez. 